\title{
Antimicrobial resistance surveillance systems: Are potential biases taken into account?
}

\author{
Olivia Rempel MLT BHSc${ }^{1}$, Johann DD Pitout MBChB M Med(Micro Path) FFPath(SA) ${ }^{2}$, \\ Kevin B Laupland MD MSc FRCPC ${ }^{3}$
}

O Rempel, JDD Pitout, KB Laupland. Antimicrobial resistance surveillance systems: Are potential biases taken into account? Can J Infect Dis Med Microbiol 2011;22(4):e24-e28.

BACKGROUND: The validity of surveillance systems has rarely been a topic of investigation.

OBJECTIVE: To assess potential biases that may influence the validity of contemporary antimicrobial-resistant (AMR) pathogen surveillance systems.

METHODS: In 2008, reports of laboratory-based AMR surveillance systems were identified by searching Medline. Surveillance systems were appraised for six different types of bias. Scores were assigned as '2' (good), ' 1 ' (fair) and ' 0 ' (poor) for each bias.

RESULTS: A total of 22 surveillance systems were included. All studies used appropriate denominator data and case definitions (score of 2). Most $(n=18)$ studies adequately protected against case ascertainment bias $($ score $=2$ ), with three studies and one study scoring 1 and 0 , respectively. Only four studies were deemed to be free of significant sampling bias (score $=2$ ), with 17 studies classified as fair, and one as poor. Eight studies had explicitly removed duplicates $($ score $=2$ ). Seven studies removed duplicates, but lacked adequate definitions $($ score $=1)$. Seven studies did not report duplicate removal $($ score $=0$ ). Eighteen of the studies were considered to have good laboratory methodology, three had some concerns ( to be poor $($ score $=0)$.

CONCLUSION: Contemporary AMR surveillance systems commonly have methodological limitations with respect to sampling and multiple counting and, to a lesser degree, case ascertainment and laboratory practices. The potential for bias should be considered in the interpretation of surveillance data.

Key Words: Antimicrobial resistance; Bias; Epidemiology; Incidence; Risk

$\mathrm{T}$ he emergence of organisms with resistance to antimicrobial agents is a paramount contemporary health care issue, and surveillance has been recognized as a fundamental component in their control (1-3). Surveillance information enables the assessment of the burden of disease, determination of risk factors, and identification of temporal trends in occurrence and resistance patterns of infectious diseases. Such information may be used to aid policy-makers in their decisions regarding health services and research funding allocation, to guide efforts into means of prevention and control, and to direct empirical antimicrobial therapy recommendations. However, the value of surveillance information is predicated on its reliability and validity. Invalid surveillance data risks wasting health care resources through misguided efforts, and may result in patient harm through inappropriate use of antimicrobial agents. Although surveillance data have been widely published and used by researchers and decision makers, little attention has been devoted to the assessment of their validity (3-10).

\section{Les systèmes de surveillance de la résistance antimicrobienne : les biais potentiels sont-ils pris en compte?}

HISTORIQUE : La validité des systèmes de surveillance est rarement l'objet d'enquête.

OBJECTIF : Évaluer les biais potentiels susceptibles d'influer sur les systèmes de surveillance des pathogènes résistants aux antimicrobiens (RAM). MÉTHODOLOGIE : En 2008, les chercheurs ont repéré des rapports sur les systèmes de surveillance des pathogènes RAM en laboratoire par des recherches dans Medline. Ils ont évalué les systèmes de surveillance en regard de six types de biais et attribué des indices de « 2 » (bon), « 1 » (modéré) et « 0 » (médiocre) à l'égard de chacun d'eux.

RÉSULTATS : Au total, 22 systèmes de surveillance ont fait partie de l'analyse. Toutes les études faisaient appel à des données utilisées en guise de dénominateur et à des définitions de cas (indice de 2). La plupart $(n=18)$ assuraient une protection pertinente contre les biais d'évaluation de cas (indice $=2$ ), trois études obtenant un indice de 1 et une, un indice de 0 . Seulement quatre études étaient réputées ne pas comporter de biais d'échantillonnage significatif (indice = 2), 17 études obtenant un résultat modéré et une, un résultat médiocre. Huit études avaient explicitement supprimé les dédoublements (indice $=2$ ), sept les avaient supprimés, mais ne comportaient pas de définition pertinente (indice $=1$ ) et sept ne précisaient pas s'ils avaient été supprimés (indice $=0$ ). Dix-huit études étaient considérées comme possédant une bonne méthodologie de laboratoire, trois s'associaient à certains problèmes (indice $=1$ ), et une était considérée comme médiocre (indice $=0$ ). CONCLUSION : Les systèmes de surveillance contemporains des pathogènes RAM comportent souvent des limites méthodologiques relativement à l'échantillonnage et aux dédoublements et, à un moindre degré, à l'évaluation des cas ainsi qu'aux pratiques de laboratoire. Le potentiel de biais devrait être pris en compte dans l'interprétation des données de surveillance.

We previously explored six potential biases that may influence surveillance systems including bias related to the use of inadequate or inappropriate denominator data (I); case definitions (II) and case ascertainment (III); sampling bias (IV); failure to deal with multiple occurrences $(\mathrm{V})$; and biases related to laboratory practice and procedures (VI) (3). To our knowledge, there have been no previous systematic attempts to examine contemporary antimicrobial-resistant (AMR) organism surveillance systems with regard to how well they protect from bias. The objective of the present study was to assess current surveillance systems for AMR organisms against the six main biases identified in our previous literature review (3).

\section{METHODS}

A sample of current surveillance systems was obtained by searching the Medline database through the PubMed interface using the terms "antimicrobial resistance" and "surveillance". The search was limited to

${ }^{1}$ O'Brien Centre for the Bachelor of Health Sciences Program, Health Sciences Centre, Faculty of Medicine, University of Calgary; ${ }^{2}$ Departments of Pathology and Laboratory Medicine and Microbiology and Infectious Diseases, University of Calgary and Alberta Health Services, Calgary;

${ }^{3}$ Departments of Medicine, Critical Care Medicine, Pathology and Laboratory Medicine, and Community Health Sciences, and Centre for

Antimicrobial Resistance, University of Calgary and Alberta Health Services, Calgary, Alberta

Correspondence: Dr Kevin B Laupland, Critical Care Medicine, Peter Lougheed Centre, 3500-26th Street Northeast, Calgary, Alberta T1Y 6J4.

Telephone 403-943-5785, fax 403-291-1491, e-mail kevin.laupland@calgaryhealthregion.ca 
TABLE 1

Consensus scores for antimicrobial resistance surveillance systems

\begin{tabular}{|c|c|c|c|c|c|c|c|c|}
\hline \multirow{2}{*}{$\begin{array}{l}\text { First author, study acronym } \\
\text { (reference[s]) }\end{array}$} & \multirow{2}{*}{ Context (country) } & \multicolumn{7}{|c|}{ Bias score categories } \\
\hline & & I & II & III & IV & V & VI & Total \\
\hline Jones, LEADER (13) & Linezolid resistance in selected species (United States) & 2 & 2 & 2 & 1 & 0 & 2 & 9 \\
\hline Du Plessis, $(31,43)$ & Resistance of Neiserria meningitidis (South Africa) & 2 & 2 & 2 & 2 & 0 & 2 & 10 \\
\hline Farrell, BSAC $(14,44,45)$ & Pneumococcal bacteremia resistance (United Kingdom) & 2 & 2 & 2 & 1 & 2 & 2 & 11 \\
\hline Gottlieb, AGAR (15) & Pneumococcal resistance (Australia) & 2 & 2 & 2 & 1 & 2 & 1 & 10 \\
\hline Oteo, EARSS $(16,46)$ & Escherichia coli resistance (Spain) & 2 & 2 & 2 & 1 & 2 & 2 & 11 \\
\hline Zhanel, CAN-ICU $(17,47)$ & Resistance in intensive care unit isolates (Canada) & 2 & 2 & 2 & 1 & 1 & 2 & 10 \\
\hline Inoue, PROTEKT $(5,18)$ & Resistance of three organisms (Japan) & 2 & 2 & 2 & 1 & 1 & 2 & 10 \\
\hline Nys (19) & Resistance in uropathogenic Escherichia coli & 2 & 2 & 2 & 1 & 2 & 2 & 11 \\
\hline WHO, WPGASP $(20,35)$ & Neiserria gonorrhoeae resistance in 17 countries & 2 & 2 & 1 & 1 & 0 & 2 & 8 \\
\hline Asbell, TRUST (21) & Susceptibility of selected ocular isolates (United States) & 2 & 2 & 2 & 1 & 1 & 2 & 10 \\
\hline Jones, MYSTIC (22) & Hospital pathogens (United States) & 2 & 2 & 0 & 1 & 0 & 2 & 7 \\
\hline Phares, ABCs $(32,41,42)$ & Group B streptococcus (United States) & 2 & 2 & 2 & 2 & 0 & 2 & 10 \\
\hline Kumar (33) & Invasive pneumococcal disease (Canada [Toronto, Ontario area]) & 2 & 2 & 2 & 2 & 2 & 1 & 11 \\
\hline Fritsche, SENTRY (23) & Ceftibiprole against bacterial isolates in three continents & 2 & 2 & 2 & 1 & 1 & 2 & 10 \\
\hline Brazier, ESCMID (24) & Gram-positive anaerobic cocci susceptibilities (Europe) & 2 & 2 & 2 & 1 & 1 & 2 & 10 \\
\hline Yoo (25) & Resistance in Pseudomonas aeruginosa isolates (Korea) & 2 & 2 & 2 & 0 & 1 & 1 & 8 \\
\hline Ofner-Agostini, CNISP (26) & Vancomycin-resistant enterococci (Canada) & 2 & 2 & 1 & 1 & 2 & 0 & 8 \\
\hline Tapsall, AGSP $(27,48)$ & Resistant of Neiserria gonorrhoeae (Australia) & 2 & 2 & 2 & 1 & 0 & 2 & 9 \\
\hline Rossi, TEST (28) & Resistance in selected isolates (South America) & 2 & 2 & 2 & 1 & 2 & 2 & 11 \\
\hline Greene, NARMS (29) & Resistance to nontyphoid salmonella (United States) & 2 & 2 & 2 & 1 & 0 & 2 & 9 \\
\hline Xiao, Mohnarin (30) & National antimicrobial resistance surveillance (China) & 2 & 2 & 2 & 1 & 2 & 2 & 11 \\
\hline Heffernan (34) & Invasive pneumococcal disease (New Zealand) & 2 & 2 & 1 & 2 & 1 & 2 & 10 \\
\hline
\end{tabular}

* I Inadequate or inappropriate denominator data; II Case definitions; III Case ascertainment; IV Sampling bias; V Failure to deal with multiple occurrences; VI biases related to laboratory practice and procedures (3). ABCs Active Bacterial Core Surveleillance; AGAR Australian Group on Antimicrobial Resistance; AGSP Australian Gonococcal Surveillance Programme; BSAC British Society for Antimicrobial Chemotherapy; CAN-ICU Canadian National Intensive Care Unit (CAN-ICU); CNSIP Canadian Nosocomial Infection Surveillance Program; EARSS European Antimicrobial Resistance Surveillance System; ESCMID European Society of Clinical Microbiology and Infectious Diseases; LEADER The Linezolid Experience and Accurate Determination of Resistance; MYSTIC Meropenem Yearly Susceptibility Test Information Collection; NARMS National Antimicrobial Monitoring System; PROTEKT Prospective Resistant Organism Tracking and Epidemilogy for the Ketolide Telithromycin; SENTRY SENTRY Antimicrobial Resistance Surveillance Program; TEST Tigecycline Evaluation and Surveillance Trial; TRUST Tracking Resistance in the United States Today. ICU Intensive care unit

include only human-based surveillance articles written in English and published in 2008. After identifying all studies meeting the above criteria, abstracts were initially screened by one author (OR) under the supervision of another (KBL) to identify relevant studies for further review. Given that surveillance is generally expected to have an ongoing component, one-time resistance surveys were excluded (11), and only studies that included ongoing, multicentric, laboratory-based surveillance that reported on at least one AMR organism were included. When multiple studies from the same surveillance system were obtained, only the first study appearing in the search results for 2008 was included for analysis. However, if methods were referenced elsewhere, then these reports were retrieved and reviewed.

A scoring guide was developed to assess the surveillance studies according to the six biases identified in our previous literature review (3). Scores were assigned as 0,1 or 2 for each of the six potential biases. A score of 0 was assigned where measures to protect from bias were either poor or not reported. Studies that reported some measures to protect against the bias under consideration were scored as 1 . Study methodologies that were well-protected against bias were scored as 2 . After assigning scores for each of the six biases, the scores were summed to obtain a total final score from zero to 12 .

Two reviewers (OR and KBL) independently reviewed and scored the selected studies. Scores were based on the selected publications alone; supplemental searching for added detail through other means, such as the Internet or by contacting authors, was not performed. If there were potentially overlapping areas of bias recognized, then each area was considered separately such that studies could not lose points for the same issue more than once. For example, if an issue surrounding case definitions also directly led to problems with case ascertainment, then a reduced score was recorded for the case definition, but case ascertainment was scored assuming an adequate case definition. Once the two independent reviews were completed, discrepancies were resolved through consensus with a third reviewer (JDDP).

Analysis was primarily descriptive. The weighted kappa statistic was calculated to assess the level of agreement between the two independent reviewers - both overall and for each of the six biases examined (12).

\section{RESULTS}

Initially, 459 abstracts were screened and, of these, 22 fulfilled the study inclusion criteria and were reviewed in detail and scored. Of these, there were five studies from the United States, four studies from Europe, three studies from Asia, three studies from Australia and New Zealand, three studies from Canada, two studies from multiple continents, and one study from each of Africa and South America. The included studies and their consensus scores are summarized in Table 1. The overall median score was 10 (range 7 to 11 ), and the weighted kappa score among the two reviewers was 0.82 .

\section{Denominator data and case definitions}

The weighted kappa for each of denominator data and case definitions was 1 . All studies scored '2' for denominator data and case definition. Of these, 18 studies examined resistance among all isolates obtained $(13-30)$. The other four were population based, and the denominator included all patients at risk for antimicrobial resistance (31-34). Because all studies based their case definition on resistance using wellestablished guidelines, case definition was not an issue for any of the surveillance studies examined. 


\section{Case ascertainment}

For case ascertainment, the weighted kappa statistic was 0.60. Eighteen of the studies scored '2' for case ascertainment (13-19,21,23-25,27-33). These studies were either population based or reported on the proportion of isolates that were resistant. It was deemed that all cases meeting the case definition were included, and cases not meeting the case definition were excluded. There were issues with case ascertainment for four of the studies examined. Three had concerns with case ascertainment because it was possible that not all isolates were tested for resistance and were, therefore, given a score of ' 1 ' because some of the isolates not tested may have met the case definition of resistance $(20,26,34)$. One study had substantial issues with case ascertainment and was deemed poorly protected from bias due to the fact that the study was describing antimicrobial resistance rates, but excluded isolates based on intrinsic resistance and was given a score of 'O' (22).

\section{Sampling bias}

The weighted kappa statistic was 0.60. Many issues were noted with sampling bias in surveillance systems. Of the 22 studies, the four population-based studies included all patients at risk for antimicrobial resistance; sampling bias was precluded because sampling was not performed and, therefore, were scored ' 2 ' for sampling bias (31-34). Seventeen studies scored ' 1 ' (13-30). Of these, seven had concerns with sampling because they asked for a certain number of consecutive isolates $(13-15,17,19,23,24)$. Another five studies had sampling issues because they asked for a certain number of isolates with no explicit statement as to the method with which these isolates were to be sampled $(18,20-22,28)$. In addition, five studies scored ' 1 ' solely on the basis that the sampling of geographical centres was not reportedly based on true random sampling $(16,26,27,29,30)$. The study scoring ' 0 ' did so because it had no systematic means of selecting participating centres based on the area it sought to measure and samples were obtained from only two laboratories (25).

\section{Multiple counting}

The weighted kappa statistic was 0.80 . Multiple counting was an area with an important risk of bias. Only eight studies removed duplicate samples and explicitly stated the criteria for doing so and were scored ' 2 ' (14-16,19,33,34). There were seven studies that scored ' 1 ' because they stated that duplicates were removed, but reported no definition of what constituted a duplicate isolate $(17,18,21,23-25,34)$. Finally, seven studies did not report whether duplicate removal was performed and were given a score of ' 0 ' $(13,20,22,27,29,31,32)$.

\section{Laboratory practices and procedures}

The weighted kappa statistic for laboratory practices and procedures was 0.60 . Laboratory practices and procedures was not a substantial area of concern for bias for most of the studies. Eighteen of the studies had reported thorough protocols, quality-assurance programs, standardized testing and/or centralized testing (13,14,16-24,27-32,34,35). Three of the studies had some concerns with laboratory practices and procedures because documentation was lacking regarding standardized testing among all laboratories or they did not report on any qualityassurance/quality-control programs in place at the laboratories $(15,25,33)$. One study had substantial concerns with a risk for bias because its laboratory methodology was poorly reported (26).

\section{DISCUSSION}

In the present study, we identified that contemporary AMR surveillance systems are commonly at risk for bias related to multiple counting and sampling procedures and, to a lesser extent, case ascertainment and laboratory procedures. We did not observe any significant problems with use of the appropriate denominator data or with case definitions in the studies included.

Multiple counting is a significant potential issue and arises when a case is counted more than once for the same episode of disease (3). While no universal 'gold standard' definition exists, it is generally accepted that only the first isolate per patient per episode of disease should be counted (36). Several studies have found that failure to remove duplicates or multiple counting of the same isolates results in an overestimate of both occurrence and rates of resistance $(3,37,38)$. An episode of disease can be based on clinical criteria or on a defined analysis period. In the case of clinical criteria, a second episode is typically defined based on a comprehensive assessment of laboratory and clinical variables such as with repeat illness following complete clinical and/or microbiological resolution of a previous episode. In many cases, particularly with laboratory-based studies, such detailed clinical information is not available and a defined analysis period is used. In these cases, repeat isolates within some time frame (eg, one month, one year) are excluded. Studies have consistently shown that increasing the period of duplicate elimination will reduce the reported incidence and antimicrobial resistance rates $(3,37,38)$.

Sampling bias occurs when the sample under study differs in some systematic way from the larger population of interest (3). One way to minimize or avoid this bias is to include all of the population of interest. However, such population-based studies are often practically difficult to conduct and, in most cases, sampling must be performed (31-34). To be unbiased, a sample should be randomly selected from the overall population of interest. This, however, does not appear to be a common practice in surveillance studies, and convenience sampling from selected laboratories is the usual and potentially highly biased practice. In multicentred studies, hospital-based laboratories - particularly academic tertiary care referral centres - are frequently over represented and, as a result, resistance rates are typically higher than in the population at-large. In addition, the time of day, day of the week, and season of the year may have a significant influence on rates of disease and antimicrobial resistance (38-40). The practice of collecting consecutive samples over a defined period may then be highly influenced by when and where these are obtained.

There are several limitations of the present report that warrant discussion. First, the six biases that we evaluated require, at least to some degree, a component of subjective interpretation, and the possibility exists that other investigators may critique the studies differently. We attempted to minimize subjective interpretation by the use of explicit prespecified criteria for scoring (Appendix). In addition, reviews were conducted independently by two reviewers with generally good or excellent agreement as indicated by the reported kappa scores. Second, our appraisal of study methodology was based on an assessment of methods as reported in the publications. We only reviewed supplemental information surrounding study methodology if it was directly referenced in the index publication under review. Therefore, it is possible that a given study may have been truly protected from a bias, but we assigned a lower score based on a lack of reporting. For example, this is likely the case for the issue of multiple counting with the ABC study $(32,41,42)$. Another possibility is that improvements in methodology not reported in retrieved publications may have been missed by not reviewing all publications from each system. Third, in an attempt to be as systematic as possible, we elected to only evaluate studies on the basis of the six measures of bias that we previously identified (3). There are undoubtedly several other potential biases and considerations that could influence the interpretation of surveillance data that were not included and are not limited to database quality, statistical analysis, and other factors such as timeliness and responsiveness of reporting. Fourth, we only obtained a sample of all current systems by limiting evaluating to all relevant publications in 2008 for practical reasons. In addition, unlike with scoring of studies, the process for selection of systems for inclusion was less systematic and some systems may have been missed. Finally, our overall scores assigned to surveillance systems should not be considered as a linear measure of the quality of study alone because we did not weight the relative importance of the six measures. For example, a study could have a 'fatal flaw' in one of the six areas of bias and be considered invalid overall, but potentially still achieve a score of 10/12. 


\section{SUMMARY}

There are several potential biases that can influence the validity of AMR surveillance information. The potential for bias should be considered in the interpretation and use of AMR surveillance data.

ACKNOWLEDGMENTS: No external funding was received in support of this study. None of the authors has any conflicts of interest to declare.

NOTE: This work was presented in part at the 50th Interscience Conference on Antimicrobial Chemotherapy (ICAAC), September 15, 2010, Boston, Massachusetts, USA

\section{APPENDIX}

\section{SCORING GUIDE \\ Reviewer: Laupland, Rempel Reference:}

\section{SECTION 1}

Inclusion criteria (must have all of the following; check if present)

- Multicentric

- Examine at least one antimicrobial resistant organism

- Laboratory based

- Human

- Ongoing

Context of study:

\section{SECTION 2}

Assessment of bias (must select one score for each bias)

\section{Denominator data}

0 Denominator data not reported or irrelevant

1 Used denominator data, but not optimal for stated objective

2 Optimal denominator data used for objective

\section{Case definition}

0 No case definition or inappropriate for objectives/design/reporting

1 Case definition used, but not clearly appropriate

2 Case definition matched to objectives/design/reporting

\section{Complete ascertainment}

0 Highly likely that cases that do not meet case definition may be included; cases that meet the case definition may have been missed or there was no systematic means of case ascertainment

1 Some cases that do not meet case definition may be included and some cases that meet the case definition may have been missed

2 All episodes fulfilling case definition included and nonrelevant cases excluded

\section{Sampling bias}

0 Arbitrary convenience or non-random sampling; not reported

1 Sample systematically derived from surveillance population, but at risk for bias in relation to time, space, and/or location

2 Either population-based or true random sample of surveillance population

\section{Multiple counting}

0 Duplicate isolates/episodes not removed or reported

1 Duplicate isolates/episodes removed, but unclear rationale or explicit criteria

2 All duplicate isolates/episodes removed with relevant and explicit criteria

\section{Laboratory practices}

0 Problems with nonstandardized testing; variable protocols; lacking quality control, testing rules; or not reported

1 Limitations in consistency, some problems with protocols, quality control

2 Central laboratory or all laboratories following identical protocol with clear criteria for testing rules, proficiency testing/quality control, and appropriate species level identification

\section{REFERENCES}

1. Conly J. Antimicrobial resistance in Canada. CMAJ 2002;167:885-91.

2. Marchese A, Schito GC. Role of global surveillance in combating bacterial resistance. Drugs 2001;61:167-73.

3. Rempel OR, Laupland KB. Surveillance for antimicrobial resistant organisms: Potential sources and magnitude of bias. Epidemiol Infect 2009;137:1665-73.

4. Bax R, Bywater R, Cornaglia G, et al. Surveillance of antimicrobial resistance - what, how and whither? Clin Microbiol Infect 2001;7:316-25.

5. Felmingham $D$. The need for antimicrobial resistance surveillance. J Antimicrob Chemother 2002;50(Suppl S1):1-7.

6. Tapsall JW. Monitoring antimicrobial resistance for public health action. Commun Dis Intell 2003;27(Suppl):S70-4.

7. Hunter PA, Reeves DS. The current status of surveillance of resistance to antimicrobial agents: Report on a meeting. J Antimicrob Chemother 2002;49:17-23.

8. Cornaglia G, Lonnroth A, Struelens M. Report from the European Conference on the Role of Research in Combating Antibiotic Resistance, 2003. Clin Microbiol Infect 2004;10:473-97.

9. Monnet DL. Toward multinational antimicrobial resistance surveillance systems in Europe. Int J Antimicrob Agents 2000;15:91-101.

10. Thacker SB, Parrish RG, Trowbridge FL. A method for evaluating systems of epidemiological surveillance. World Health Stat Q 1988;41:11-8.

11. Thacker SB, Berkelman RL. Public health surveillance in the United States. Epidemiol Rev 1988;10:164-90.

12. VassarStats: Web site for statistical computation. $<$ http://faculty. vassar.edu/lowry/kappa.html> (Accessed on July 4, 2011).

13. Jones RN, Ross JE, Castanheira M, Mendes RE. United States resistance surveillance results for linezolid (LEADER Program for 2007). Diagn Microbiol Infect Dis 2008;62:416-26.

14. Farrell DJ, Felmingham D, Shackcloth J, et al. Non-susceptibility trends and serotype distributions among Streptococcus pneumoniae from community-acquired respiratory tract infections and from bacteraemias in the UK and Ireland, 1999 to 2007.

J Antimicrob Chemother 2008;62(Suppl 2):ii87-95.

15. Gottlieb T, Collignon PJ, Robson JM, Pearson JC, Bell JM. Prevalence of antimicrobial resistances in Streptococcus pneumoniae in Australia, 2005: report from the Australian Group on Antimicrobial Resistance. Commun Dis Intell 2008;32:242-9.

16. Oteo J, Campos J, Lazaro E, et al. Increased amoxicillin-clavulanic acid resistance in Escherichia coli blood isolates, Spain. Emerg Infect Dis 2008;14:1259-62.

17. Zhanel GG, DeCorby M, Nichol KA, et al. Antimicrobial susceptibility of 3931 organisms isolated from intensive care units in Canada: Canadian National Intensive Care Unit Study, 2005/2006. Diagn Microbiol Infect Dis 2008;62:67-80.

18. Inoue M, Farrell DJ, Kaneko K, et al. Antimicrobial susceptibility of respiratory tract pathogens in Japan during PROTEKT years 1-5 (1999-2004). Microb Drug Resist 2008;14:109-17.

19. Nys S, Terporten PH, Hoogkamp-Korstanje JA, Stobberingh EE. Trends in antimicrobial susceptibility of Escherichia coli isolates from urology services in The Netherlands (1998-2005). J Antimicrob Chemother 2008;62:126-32.

20. WHO. Surveillance of antibiotic resistance in Neisseria gonorrhoeae in the WHO Western Pacific Region, 2006. Commun Dis Intell 2008;32:48-51.

21. Asbell PA, Colby KA, Deng S, et al. Ocular TRUST: Nationwide antimicrobial susceptibility patterns in ocular isolates. Am J Ophthalmol 2008;145:951-8.

22. Jones RN, Kirby JT, Rhomberg PR. Comparative activity of meropenem in US medical centers (2007): Initiating the 2nd 
decade of MYSTIC program surveillance. Diagn Microbiol Infect Dis 2008;61:203-13.

23. Fritsche TR, Sader HS, Jones RN. Antimicrobial activity of ceftobiprole, a novel anti-methicillin-resistant Staphylococcus aureus cephalosporin, tested against contemporary pathogens: Results from the SENTRY Antimicrobial Surveillance Program (2005-2006). Diagn Microbiol Infect Dis 2008;61:86-95.

24. Brazier J, Chmelar D, Dubreuil L, et al. European surveillance study on antimicrobial susceptibility of Gram-positive anaerobic cocci. Int J Antimicrob Agents 2008;31:316-20.

25. Yoo J, Sohn ES, Chung GT, et al. Five-year report of national surveillance of antimicrobial resistance in Pseudomonas aeruginosa isolated from non-tertiary care hospitals in Korea (2002-2006). Diagn Microbiol Infect Dis 2008;60:291-4.

26. Ofner-Agostini M, Johnston BL, Simor AE, et al. Vancomycinresistant enterococci in Canada: Results from the Canadian nosocomial infection surveillance program, 1999-2005. Infect Control Hosp Epidemiol 2008;29:271-4.

27. Tapsall JW, Limnios EA, Murphy D. Analysis of trends in antimicrobial resistance in Neisseria gonorrhoeae isolated in Australia, 1997-2006. J Antimicrob Chemother 2008;61:150-5.

28. Rossi F, Garcia P, Ronzon B, Curcio D, Dowzicky MJ. Rates of antimicrobial resistance in Latin America (2004-2007) and in vitro activity of the glycylcycline tigecycline and of other antibiotics. Braz J Infect Dis 2008;12:405-15.

29. Greene SK, Stuart AM, Medalla FM, Whichard JM, Hoekstra RM, Chiller TM. Distribution of multidrug-resistant human isolates of MDR-ACSSuT Salmonella Typhimurium and MDR-AmpC Salmonella Newport in the United States, 2003-2005. Foodborne Pathog Dis 2008;5:669-80.

30. Xiao YH, Wang J, Li Y. Bacterial resistance surveillance in China: A report from Mohnarin 2004-2005. Eur J Clin Microbiol Infect Dis 2008;27:697-708.

31. du Plessis M, von Gottberg A, Cohen C, de Gouveia L, Klugman KP. Neisseria meningitidis intermediately resistant to penicillin and causing invasive disease in South Africa in 2001 to 2005. J Clin Microbiol 2008;46:3208-14.

32. Phares CR, Lynfield R, Farley MM, et al. Epidemiology of invasive group B streptococcal disease in the United States, 1999-2005. JAMA 2008;299:2056-65.

33. Kumar D, Humar A, Plevneshi A, et al. Invasive pneumococcal disease in adult hematopoietic stem cell transplant recipients: A decade of prospective population-based surveillance. Bone Marrow Transplant 2008;41:743-7.

34. Heffernan HM, Martin DR, Woodhouse RE, Morgan J, Blackmore TK. Invasive pneumococcal disease in New Zealand 1998-2005: Capsular serotypes and antimicrobial resistance. Epidemiol Infect 2008;136:352-9.

35. Surveillance of antibiotic susceptibility of Neisseria gonorrhoeae in the WHO western Pacific region 1992-4. WHO Western Pacific
Region Gonococcal Antimicrobial Surveillance Programme. Genitourin Med 1997;73:355-61.

36. Shannon KP, French GL. Validation of the NCCLS proposal to use results only from the first isolate of a species per patient in the calculation of susceptibility frequencies. J Antimicrob Chemother 2002;50:965-9.

37. Shannon KP, French GL. Antibiotic resistance: Effect of different criteria for classifying isolates as duplicates on apparent resistance frequencies. J Antimicrob Chemother 2002;49:201-4.

38. Laupland KB, Ross T, Pitout JD, Church DL, Gregson DB. Investigation of sources of potential bias in laboratory surveillance for anti-microbial resistance. Clin Invest Med 2007;30:E159-66.

39. Guevara S, Soley C, Arguedas A, Porat N, Dagan R. Seasonal distribution of otitis media pathogens among Costa Rican children. Pediatr Infect Dis J 2008;27:12-6.

40. Rossello-Urgell J, Vaque-Rafart J, Armadans-Gil LL, et al. The importance of the day of the week and duration of data collection in prevalence surveys of nosocomial infections. J Hosp Infect 2004;57:132-8.

41. Schuchat A, Hilger T, Zell E, et al. Active bacterial core surveillance of the emerging infections program network. Emerg Infect Dis 2001;7:92-9.

42. Schuchat A, Robinson K, Wenger JD, et al. Bacterial meningitis in the United States in 1995. Active Surveillance Team. N Engl J Med 1997;337:970-6.

43. Huebner RE, Klugman KP, Matai U, Eggers R, Hussey G. Laboratory surveillance for Haemophilus influenzae type B meningococcal, and pneumococcal disease. Haemophilus Surveillance Working Group. S Afr Med J 1999;89:924-5.

44. Reynolds R, Hope R, Williams L. Survey, laboratory and statistical methods for the BSAC Resistance Surveillance Programmes. J Antimicrob Chemother 2008;62(Suppl 2):ii15-28.

45. Reynolds R, Lambert PC, Burton PR. Analysis, power and design of antimicrobial resistance surveillance studies, taking account of inter-centre variation and turnover. J Antimicrob Chemother 2008;62 (Suppl 2):ii29-39.

46. Oteo J, Lazaro E, de Abajo FJ, Baquero F, Campos J. Antimicrobial-resistant invasive Escherichia coli, Spain. Emerg Infect Dis 2005;11:546-53.

47. Zhanel GG, DeCorby M, Laing N, et al. Antimicrobial-resistant pathogens in intensive care units in Canada: Results of the Canadian National Intensive Care Unit (CAN-ICU) study, 2005-2006. Antimicrob Agents Chemother 2008;52:1430-7.

48. Penicillin sensitivity of gonococci in Australia: Development of Australian gonococcal surveillance programme. Members of the Australian Gonococcal Surveillance Programme. Br J Vener Dis 1984;60:226-30. 


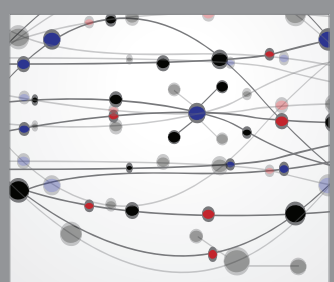

The Scientific World Journal
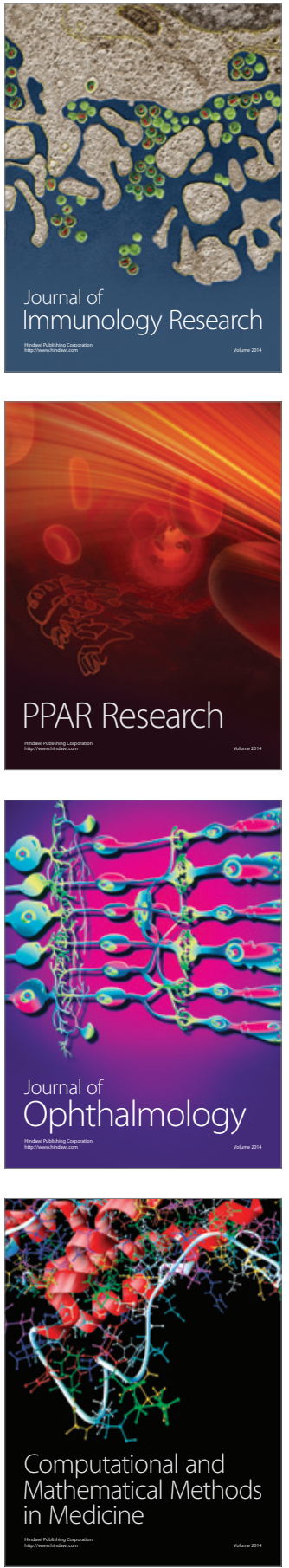

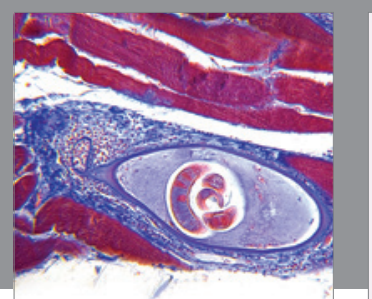

Gastroenterology Research and Practice

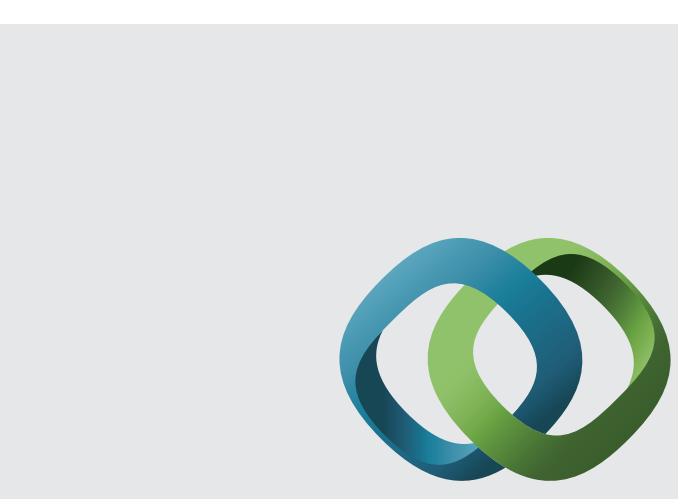

\section{Hindawi}

Submit your manuscripts at

http://www.hindawi.com
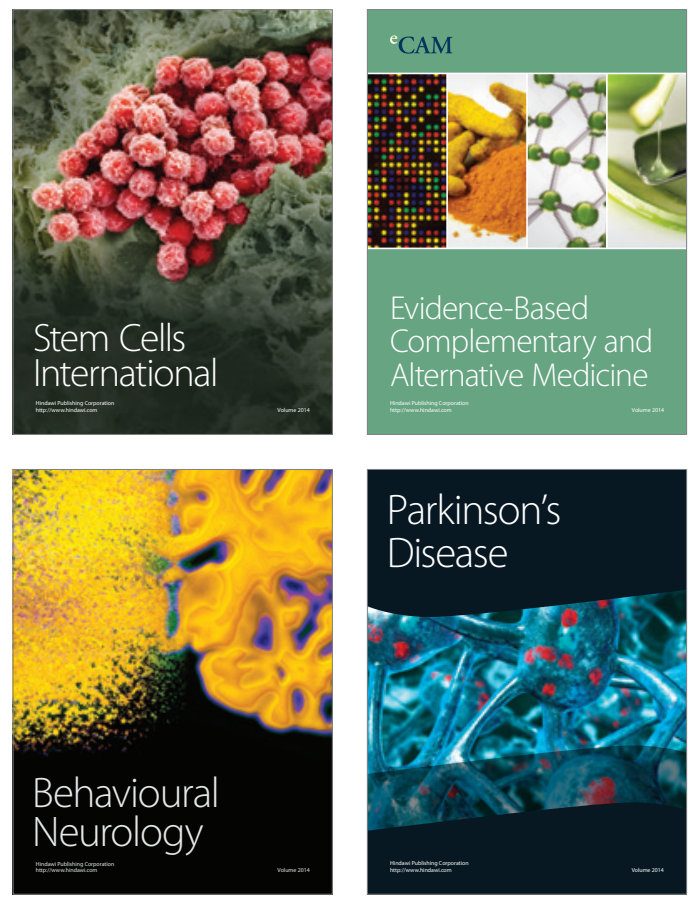
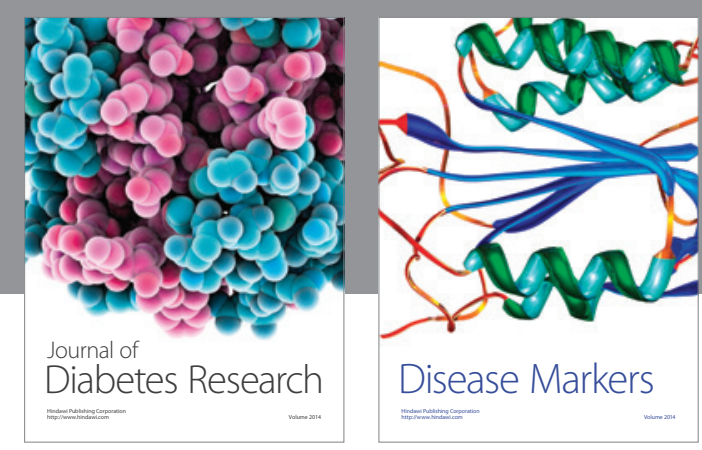

Disease Markers
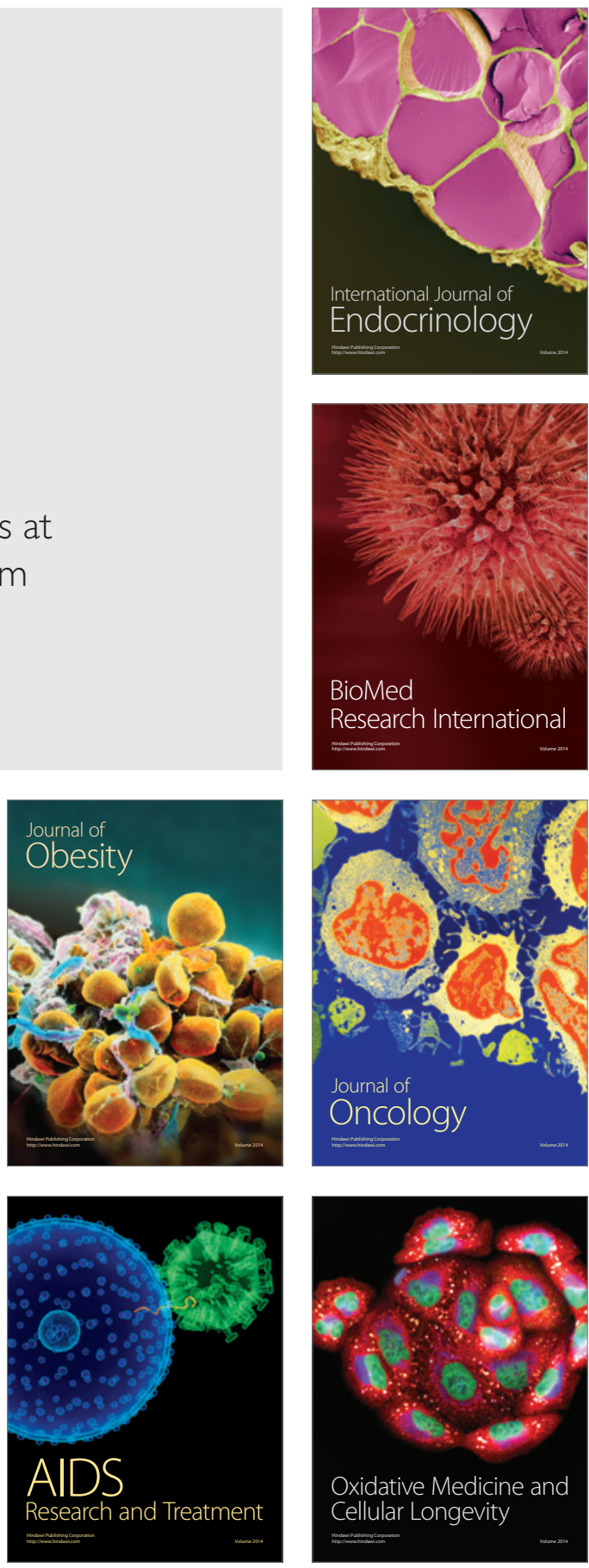